\title{
Exposure to HIV-protease inhibitors selects for increased expression of P-glycoprotein (ABCBI) in Kaposi's sarcoma cells
}

\author{
MB Lucia',2, R Anu', M Handley', J-P Gillet', C-P Wu ${ }^{1,3}$, GM De Donatis', R Cauda ${ }^{2}$ and MM Gottesman*,1 \\ 'Laboratory of Cell Biology, Center for Cancer Research, National Cancer Institute, NIH, 37 Convent Drive, Room 2108, Bethesda, MD 20892, USA; \\ ${ }^{2}$ Department of Infectious Diseases, Catholic University, Rome, Italy
}

\begin{abstract}
BACKGROUND: Given that HIV-protease inhibitors (HIV-PIs) are substrates/inhibitors of the multidrug transporter ABCBI, can induce $A B C B I$ expression, and are used in combination with doxorubicin for AIDS-Kaposi's Sarcoma (KS) treatment, the role that ABCBI plays in mediating multidrug resistance (MDR) in a fully transformed KS cell line (SLK) was explored.

METHODS: The KS cells were exposed to both acute and chronic treatments of physiological concentrations of different HIV-PIs (indinavir, nelfinavir, atazanavir, ritonavir, or lopinavir), alone or together with doxorubicin. The $A B C B I m R N A$ and protein expression levels were then assessed by qRT-PCR and western blotting, flow cytometry, and immunofluorescence.

RESULTS: Chronic treatment of SLK cells with one of the five HIV-PIs alone or together resulted in increased resistance to doxorubicin. Co-treatment with one of the HIV-Pls in combination with doxorubicin resulted in a synergistic increase in resistance to doxorubicin, and the degree of resistance was found to correlate with the expression of ABCBI. The SLK cells were also revealed to be cross-resistant to the structurally unrelated drug paclitaxel.

CONCLUSION: These studies suggest that ABCBI is primarily responsible for mediating MDR in SLK cells selected with either HIV-PIs alone or in combination with doxorubicin. Therefore, the roles that $A B C B I$ and drug cocktails play in mediating MDR in KS in vivo should be evaluated.

British Journal of Cancer (20II) I 05, 5I3-522. doi:I0.1038/bjc.201।.275 www.bjcancer.com

(C) 20 II Cancer Research UK
\end{abstract}

Keywords: P-glycoprotein; ABCBI; Kaposi's sarcoma; HIV-protease inhibitors; multidrug resistance

Despite recent advances in the treatment of cancer, drug resistance is still the major cause of anticancer chemotherapy failure in the clinic. Resistance manifests itself as an initial lack of a significant response to treatment or regrowth of a tumour after an initial response. Under these circumstances, tumour cells frequently exhibit simultaneous resistance to multiple structurally unrelated anticancer drugs, a phenotype known as multidrug resistance (MDR) (Gottesman et al, 2002). A major cause of the MDR phenotype is the overexpression in tumour cells of members of a highly conserved family of transmembrane proteins characterised by an ATP-binding cassette $(\mathrm{ABC})$, that is, the $\mathrm{ABC}$ superfamily of transporters (Gottesman et al, 2002). The ABC transporters efflux structurally unrelated compounds in an ATP-dependent manner, lowering the intracellular drug concentration (Gottesman et al, 2002). The paradigm for membrane-based mechanisms of cytotoxic drug resistance is P-glycoprotein (P-gp/ABCB1) selected by the MDR1 gene that functions to efflux natural cytotoxic compounds such as anthracyclines, vinca alkaloids, and taxanes from the cells (Gottesman et al, 2002). However, at least 11 other transporters have been shown to cause resistance to at least one agent (Szakacs et al, 2006). Modulators of the function of $\mathrm{ABC}$

\footnotetext{
*Correspondence: Dr MM Gottesman; E-mail: mgottesman@nih.gov ${ }^{3}$ Current address: Chang Gung University, Department of Physiology and Pharmacology, Taipei, Taiwan

Revised 17 June 2011; accepted 21 June 201 I
}

transporters have been used in the attempt to overcome MDR (Gottesman et al, 2002).

Kaposi's sarcoma (KS), a multifocal tumour of endothelial origin, remains the second most frequent tumour in HIV-infected patients worldwide. Although its incidence has significantly decreased in the highly active antiretroviral therapy (HAART) era (Boshoff and Weiss, 2002), it has become the most common cancer in Sub-Saharan Africa (Sasco et al, 2010). For advanced AIDS-related KS with extensive cutaneous and/or visceral manifestations, systemic chemotherapy in combination with HAART is indicated (Bower et al, 2008). However, despite widespread availability of these therapies, a long-lasting and complete remission is achieved in only half the patients (Nguyen et al, 2008). For patients with refractory or recurrent AIDS-KS, treatment algorithms are less well defined. However, taxanes are currently recommended in patients who had previously received anthracyclines (Dhillon et al, 2005; Bower et al, 2008).

The KS aetiology as well as current drug regimens for AIDS (HAART) and AIDS-KS (anthracyclines) may induce and/or select for a MDR phenotype through altered expression/function of $A B C$ transporters. The KS cells are endothelial-derived cells infected with and transformed by Kaposi's sarcoma-associated herpesvirus (KSHV) (Dittmer and Krown, 2007). The KS spindle cells express MRP1 and ABCB1. However, the mechanism by which these proteins are expressed (i.e., induction $v s$ selection) and whether these proteins play a role in mediating drug resistance is not known (Schwartsmann et al, 1989; Gupta et al, 1998). The HIV-protease 
inhibitors (HIV-PIs) are substrates/inhibitors of the $\mathrm{ABC}$ transporters ABCB1, ABCG2, ABCC1, and ABCC2 (Lee et al, 1998); induce and/or select for ABCB1 in human tumour cells (Perloff et al, 2000; Vishnuvardhan et al, 2003); and sensitise cells to chemotherapeutics such as vincristine, vinblastine, and doxycycline in an HIV-PI-dependent manner. Furthermore, anthracyclines are substrates of many of the $\mathrm{ABC}$ transporters (such as ABCB1, ABCG2, $A B C C 1$, and $A B C C 2$ ) and both acute and chronic treatment with anthacyclines alone can induce $\mathrm{ABCB} 1$ expression resulting in an MDR phenotype (Gottesman et al, 2002). Previously, Dupuis et al (2002) demonstrated that vinblastine-selected MDR CEM cells treated with HIV-PIs (including ritonavir and saquinavir) sensitised the cells to chemotherapeutics most likely by acting as inhibitors for ABCB1. They found that co-treatment of CEM cells with ritonavir or saquinavir and a chemotherapeutic (vinblastine, vincristine, or doxorubicin) potentiated chemotherapeutic cytotoxicity, and that saquinavir can induce ABCB1 expression in CEM cells (Dupuis et al, 2002, 2003a, 2003b). However, acute and chronic treatment with each of the HIV-PIs alone or the combination of HIV-PIs with anthracyclines, the current drug regimen for AIDS-KS, and their roles in an ABCB1-dependent MDR phenotype have never been explored.

Although advanced AIDS-KS may show partial response or regrowth (Evans et al, 2002), induction/selection of MDR in KS-derived cells has not yet been examined, although KS spindle cells express the ABC transporters (Schwartsmann et al, 1989; Gupta et al, 1998) and the individual drugs alone from the drug regimen for AIDS-KS (HIV-PIs and anthracyclines) can induce or select cells that express ABCB1. In the present study, we verified the selectability of the MDR phenotype in a fully transformed KS-derived cell line following prolonged exposure to doxorubicin. Furthermore, KS cells were exposed to both acute and chronic treatments of physiological concentrations of different HIV-PIs (indinavir, nelfinavir, atazanavir, ritonavir, or lopinavir) alone or together with doxorubicin.

\section{MATERIALS AND METHODS}

\section{Drugs and chemicals}

The HIV-PIs indinavir sulphate, nelfinavir, ritonavir, atazanavir sulphate, and lopinavir were obtained through the NIH AIDS Research and Reference Program, Division of AIDS, NIAID, NIH (Bethesda, MD, USA). Further quantities of indinavir sulphate and ritonavir were kindly provided by Merck (West Point, PA, USA) and Abbott Labs (North Chicago, IL, USA). The HIV-PIs were dissolved in dimethyl sulphoxide (DMSO - maximum content $0.5 \% \mathrm{v} / \mathrm{v}$, a concentration that was found not to influence the results of the assays) with the exception of indinavir, soluble in aqua bidest. Rhodamine 123 (Rh123), MTT (3-4,5-dimethylthiazol2-yl-2,5-diphenyl tetrazolium bromide), doxorubicin hydrochloride, and paclitaxel were purchased from Sigma Aldrich (St Louis, MO, USA) whereas Cyclosporine A was from Calbiochem (EMD Chemicals, Gibbstown, NJ, USA).

\section{Cells and culture conditions}

The KS tumour-derived cell line SLK (Herndier et al, 1994) was provided by the NIH AIDS Research and Reference Program, Division of AIDS, NIAID, NIH. Cells were cultured in RPMI-1640 (Gibco BRL, Gran Island, NY, USA) containing 10\% fetal calf serum (FCS), 1\% L-glutamine, and $1 \%$ penicillin-streptomycin in humidified atmosphere with $5 \% \mathrm{CO}_{2}$ at $37^{\circ} \mathrm{C}$. This cell line, similar to $\mathrm{KS}$, is fully transformed and tumourigenic in mice but has lost the KSHV genome in culture (O'Hara et al, 2009). Doxorubicin and HIV-PI-resistant SLK subclones were selected from the original drug-sensitive parent SLK cell line by exposure to increasing concentrations of the respective drug. Accordingly, four sublines designated as SLK-D0.02, -D0.04, -D0.09 and -D2 were developed by exposing the parental cells to $0.02,0.04,0.09$, or $2 \mu \mathrm{M}$ doxorubicin, respectively. The SLK cells were also challenged with five different HIV-PIs, indinavir sulphate (IDV), nelfinavir (NFV), ritonavir (RTV), atazanvir sulphate (ATV), and lopinavir (LPV). All of the HIV-PIs chosen are documented substrates/inhibitors of ABC transporters (Lee et al, 1998; Srinivas et al, 1998; Vishnuvardhan et al, 2003). The corresponding SLK-PI sublines were obtained by incubating cells with indinavir at concentrations of 10,30 , or $50 \mu \mathrm{M}$, resulting in IDV10, IDV30, and IDV50, respectively; nelfinavir at concentrations of 2,5 , and $10 \mu \mathrm{M}$, resulting in NFV2, NFV5, and NFV10, respectively; 1, 5, and $10 \mu \mathrm{M}$ atazanavir resulting in ATV1, ATV5, and ATV10, respectively; $1,2.5,5,10$, or $20 \mu \mathrm{M}$ ritonavir resulting in RTV1, RTV2.5, RTV5, RTV10, or RTV20, respectively; 1 and $10 \mu \mathrm{M}$ lopinavir resulting in LPV1 and LPV10, respectively; and $10 \mu \mathrm{M}$ lopinavir plus $2.5 \mu \mathrm{M}$ ritonavir resulting in LPV10/RTV2.5. Three SLK sublines were obtained through selection with $0.02 \mu \mathrm{M}$ doxorubicin plus $5 \mu \mathrm{M}$ of indinavir, nelfinavir, atazanavir, or ritonavir and named D/IDV5, D/NFV5, D/ATV5, and D/RTV5, respectively. In addition, a subline named D/LPV10/RTV5 was selected through exposure to doxorubicin $0.02 \mu \mathrm{M}$ and 10 and $5 \mu \mathrm{M}$ of lopinavir and ritonavir, respectively. The SLK cells were exposed to step-wise increasing concentrations of doxorubicin and HIV-PIs for 8 and 6 months, respectively. At 3 days before and during experiments, all selective drugs were omitted. The human epidermoid carcinoma, KB-3-1, and a KB-3-1 variant that overexpresses $\mathrm{ABCB} 1$, KB-V1, were cultured in Dulbecco's modified Eagle's medium (DMEM; Gibco) supplemented with 10\% FCS, 1\% L-glutamine, and $1 \%$ penicillin-streptomycin and were used as negative and positive controls for typical MDR1-expressing cells.

\section{Western blot analysis}

For membrane protein extraction, the cells were lysed in ice-cold radioimmunoprecipitation assay buffer (RIPA) containing $2 \%$ Triton X-100, $40 \mathrm{~mm}$ Tris ( $\mathrm{pH} 7.2$ ), $300 \mathrm{~mm} \mathrm{NaCl,} 10 \mathrm{~mm}$ EDTA, $500 \mathrm{~mm} \mathrm{NaF}$, and $100 \mathrm{~mm} \mathrm{Na}_{3} \mathrm{Vo}_{4}$ supplemented with Complete Protease Inhibitors Cocktail (Sigma-Aldrich). Lysates were cleared by centrifugation at $4{ }^{\circ} \mathrm{C}$, solubilised in $5 \times$ SDS supplemented with $1 \mathrm{~mm}$ DTT, and total protein concentration was determined by a bicinchoninic acid protein assay (Pierce, Rockford, IL, USA) with bovine serum albumin (BSA) as standard. Proteins $(50 \mu \mathrm{g})$ were resolved on Nu-Page 3-8\% Tris acetate gels (Life Technologies, Invitrogen, Carlsbad, CA, USA) and transferred to nitrocellulose membrane (Bio-Rad, Hercules CA, USA). Blots were blocked for nonspecific binding in Tris-buffered saline (TTBS) buffer containing $15 \mathrm{~mm}$ Tris, $154 \mathrm{~mm} \mathrm{NaCl}, 0.1 \%$ Triton $\mathrm{X}-100$, and $5 \%$ goat serum (Invitrogen). Membranes were incubated overnight at room temperature with the primary antibody against ABCB1 (C219, $1: 1000)$ diluted in TTBS buffer plus $5 \%$ goat serum. Blots were then probed with anti-glyceraldehyde-3-phosphate dehydrogenase (GAPDH, 1:800 000; Applied Biosystems, Foster City, CA, USA). Membranes were washed in TTBS and incubated with an antimouse horseradish peroxidase-conjugated secondary antibody (1:10000; Pierce). After the blots were washed with TTBS, immunoreactive bands were visualised using the enhanced chemiluminescence detection kit (ECL, Perkin Elmer, Waltham, MA, USA) and exposed to autoradiographic film (Kodak, purchased from Sigma Aldrich). The intensity of the bands was quantified using ImageQuant TL software (GE Healthcare Biosciences, Pittsburgh, PA, USA). The protein level of ABCB1 was normalised relative to the protein level of GAPDH.

\section{Flow cytometry}

Expression of surface ABCB1 was detected by flow cytometry using the MRK-16 antibody as previously reported (Aleman et al, 2003), 
with slight modifications. Per sample, 10000 events were collected and analysed on a FACSort flow cytometer equipped with Cell Quest software (Becton Dickinson, Franklin Lakes, NJ, USA). TheRh123 efflux assay was used to assess the functional activity of $\mathrm{ABCB} 1$ in the presence or absence of the inhibitor cyclosporine A (CsA) (Foxwell et al, 1989). Briefly, cells $\left(5 \times 10^{5}\right)$ were incubated at $37^{\circ} \mathrm{C}$ in the dark for $45 \mathrm{~min}$ in $4 \mathrm{ml}$ of Iscove's modified Dulbecco's medium (IMDM) supplemented with 5\% FCS containing $\mathrm{Rh} 123\left(0.5 \mu \mathrm{g} \mathrm{ml}^{-1}\right)$, and washed and resuspended in IMDM $5 \%$ FCS without Rh123 for an additional $45 \mathrm{~min}$. Cells were then washed and immediately analysed for intracellular Rh123 fluorescence on a FACSort flow cytometer. A minimum of 10000 events were collected for all samples.

\section{Immunofluorescence}

Cells were fixed with a $3.7 \%$ glyceraldehyde solution dissolved in phosphate-buffered saline (PBS) for $10 \mathrm{~min}$ at room temperature, followed by permeabilisation in PBS-0.5\% Triton X-100. After blocking in $1 \%$ BSA in PBS, cells were washed in PBS and incubated with anti-ABCB1 MRK-16 antibody (1:500). After extensive washing, the cells were stained with goat anti-mouse conjugated with Alexa Fluor 488 ( $1: 1000$, Invitrogen), washed, and mounted with Vectashield (Vector Laboratories, Burlingame, CA, USA) mounting medium containing the DNA stain 4',6-diamidino2-phenylindole (DAPI). Cell preparations were observed under a confocal laser scanning fluorescence microscope (LSM510, Carl Zeiss, MicroImaging, Thornwood, NY, USA).

\section{Preparation of total RNA}

Total RNA from SLK cell lines was prepared using an RNeasy Micro kit (Qiagen, Valencia, CA, USA) as per the manufacturer's instructions. RNA was quantitated using NanoDrop ND-1000 spectrophotometer (NanoDrop Technologies Inc., Wilmington, DE, USA). The integrity of the RNA samples was assessed using an Agilent 2100 Bioanalyser (Agilent Technologies, Foster City, CA, USA) and then stored at $-80^{\circ} \mathrm{C}$.

\section{Reverse transcription}

Synthesis of cDNA from $1 \mu \mathrm{g}$ total RNA in a $20 \mu \mathrm{l}$ reaction volume was carried out using the High-Capacity cDNA kit with RNAse inhibitor (Applied Biosystems) as per the manufacturer's instructions. The reverse transcription conditions were as follows: $10 \mathrm{~min}$ at $25^{\circ} \mathrm{C}, 120 \mathrm{~min}$ at $37^{\circ} \mathrm{C}$, and $5 \mathrm{~min}$ at $85^{\circ} \mathrm{C}$. Following reverse transcription, cDNA was stored at $4{ }^{\circ} \mathrm{C}$.

\section{Taqman-based qRT - PCR}

Expression levels of the $A B C B 1$ (MDR1/P-gp) gene were measured using the Hs00184491_m1 assay (Applied Biosystems); 18S was used as a housekeeping gene, Hs99999901_s1. In addition, $100 \mathrm{ng}$ of cDNA was mixed with $2 \times$ Taqman Universal PCR Master Mix (Applied Biosystems), loaded in triplicate on a 96-well plate, and run on an ABI Prism 7900 HT Sequence Detection System (Applied Biosystems) as per the manufacturer's instructions. Expression data were analysed using RQ Manager software (Applied Biosystems).

\section{MTT cytotoxicity assays}

Cells were plated into flat-bottom 96 -well plate at $2 \times 10^{3}-5 \times 10^{3}$ per well and incubated for $24 \mathrm{~h}$ at $37^{\circ} \mathrm{C}$ in $5 \% \mathrm{CO}_{2}$ before addition of various concentrations of chemotherapeutic agents to the medium and incubated for another $72 \mathrm{~h}$. After removal of medium, MTT $\left(0.5 \mathrm{mg} \mathrm{ml}^{-1}\right)$ in IMDM growth medium was added to each well. The plates were incubated at $37^{\circ} \mathrm{C}$ under $5 \% \mathrm{CO}_{2}$ for $4 \mathrm{~h}$. The
MTT solution was then removed from the wells, and $100 \mu \mathrm{l}$ acidified ethanol solution was added to dissolve the formazan crystals. After $15 \mathrm{~min}$, the absorbance at $560 \mathrm{~nm}$ with a reference wavelength of $630 \mathrm{~nm}$ was read with a SpectraMax 384 microplate reader (Molecular Devices, Sunnyvale, CA, USA). Dose-response curves were plotted and the concentrations that gave $50 \%$ inhibition of cell growth $\left(\mathrm{IC}_{50}\right)$ were calculated. The fold resistances were calculated from the ratio of the $\mathrm{IC}_{50}$ of the drug-exposed cell line to the $\mathrm{IC}_{50}$ of the sensitive parental SLK cells (resistance factor (RF)). Survival of cells that were not incubated with drug was expressed as $100 \%$. Triplicate wells were used for each treatment. Assays were performed at least three times.

\section{Statistical analysis}

Data are presented as means \pm s.d. and were analysed using GraphPad Prism Version 5.0 and InStat Version 3.05 (GraphPad Software, San Diego, CA, USA). Differences were compared using Student's $t$-test. A $P$-value of $\leqslant 0.05$ was considered significant. Drug combinations were evaluated for their ability to promote resistance synergistically or additively using the Bliss Model of Independence (Fitzgerald et al, 2006). The model states that in case two drugs $\mathrm{A}$ and $\mathrm{B}$ contribute additively to the resistance, then their combined effect can be described by the formula: $\mathrm{IC}_{50 \mathrm{~A}+\mathrm{B}}=\mathrm{IC}_{50 \mathrm{~A}}+\mathrm{IC}_{50 \mathrm{~B}}-\mathrm{IC}_{50 \mathrm{~A}} \times \mathrm{IC}_{50 \mathrm{~B}}$ where the $\mathrm{IC}_{50 \mathrm{~A}}$ and $\mathrm{IC}_{50 \mathrm{~B}}$ are the half-maximal inhibitory concentrations for doxorubicin and paclitaxel in cells pretreated with the compound A or B, respectively. The expected values obtained were compared with the ones experimentally determined using Student's $t$-test with a significance level of $P \leqslant 0.05$. Analysis was performed using Sigma Plot 11.0 (Systat Software, Inc., Chicago, IL, USA).

\section{RESULTS}

Long-term exposure to doxorubicin and HIV-PIs results in the development of resistance in SLK cells

Because of the fact that multidrug-resistant KS cells in HIV patients receiving HAART were reported, we wanted to determine if treatment with doxorubicin or HIV-PI treatment alone could induce/select resistant KS cells that exhibited a multidrug-resistant phenotype in vitro. Therefore, dose-response curves to doxorubicin and paclitaxel for the parental cell lines as well as cell lines exposed to HIV-PI or doxorubicin for 6-8 months were generated using MTT assays and the $\mathrm{IC}_{50}$ for doxorubicin and paclitaxel for each cell line was determined.

Initially, the $\mathrm{IC}_{50}$ values for doxorubicin were determined in the parental as well as in four doxorubicin-resistant cell lines. The $\mathrm{IC}_{50}$ values obtained from the dose-response curves demonstrate that long-term incubation with doxorubicin led to a 2.4 - to 12.5 -fold increase in $\mathrm{IC}_{50}$ and that the fold increase in resistance correlated with the increase in the doxorubicin concentration used for treatments where D0.02 $<\mathrm{D} 0.04<\mathrm{D} 0.09<\mathrm{D} 0.2$ (Table 1). The SLK-DOX cell lines selected with the lowest physiological concentrations of doxorubicin $(0.02$ and $0.04 \mu \mathrm{M}$; Mou et al, 1997) were then challenged with a different MDR-related drug, paclitaxel, a taxane compound. A clear cross-resistance of 6.3- to 47.7-fold resistance was observed (Table 2).

The HIV-PI-treated SLK cell lines were also analysed for sensitivity to doxorubicin. As shown in Table 1, HIV-PIs select for a significant increase of drug resistance, with a resistance factor ranging from 1.4 to 3.4 compared with SLK parent cells. Resistance to doxorubicin in HIV-PI-treated cells revealed that RTV2.5< ATV $1<$ NFV2 $<$ NFV5 $<$ IDV50 (Table 1 ). An overall increase in doxorubicin resistance was detected for almost all HIV-PI-selected SLK cell lines (Table 1). 
Table I Growth inhibitory concentrations $\left(\mathrm{IC}_{50}\right)$ and resistance factor (RF) to doxorubicin of parental and drug-selected SLK cell lines

\begin{tabular}{|c|c|c|c|c|}
\hline Treatment & $\begin{array}{l}\text { Concentration } \\
\qquad(\mu \mathrm{M})\end{array}$ & $I_{50}(\mu \mathrm{M})$ & $\begin{array}{c}\text { IC }_{50}(\mu \mathrm{M}) \\
\text { SLK } \\
\text { parent }\end{array}$ & $\begin{array}{c}\text { RF } \\
\left(I C_{50} / I C_{50}\right. \\
\text { SLK parent })\end{array}$ \\
\hline \multirow[t]{4}{*}{ Doxorubicin } & 0.02 & $1.42 \pm 0.32 *$ & $0.59 \pm 0.24$ & 2.40 \\
\hline & 0.04 & $2.76 \pm 0.6 *$ & $0.59 \pm 0.24$ & 4.67 \\
\hline & 0.09 & $3.72 \pm 0.56^{*}$ & $0.59 \pm 0.24$ & 6.30 \\
\hline & 0.2 & $7.4 \pm 1.01^{*}$ & $0.59 \pm 0.24$ & 12.54 \\
\hline \multirow[t]{3}{*}{ Indinavir } & 10 & $0.794 \pm 0.172$ & $0.59 \pm 0.24$ & 1.34 \\
\hline & 30 & $1 \pm 0.166$ & $0.59 \pm 0.24$ & 1.69 \\
\hline & 50 & $2.05 \pm 0.27 *$ & $0.59 \pm 0.24$ & 3.46 \\
\hline Doxorubicin/indinavir & $0.02 / 5$ & $1.79 \pm 0.3 *$ & $0.59 \pm 0.24$ & 3.02 \\
\hline \multirow[t]{3}{*}{ Nelfinavir } & 2 & $1.21 \pm 0.30 *$ & $0.59 \pm 0.24$ & 2.05 \\
\hline & 5 & $1.74 \pm 0.33^{*}$ & $0.59 \pm 0.24$ & 2.95 \\
\hline & 10 & $0.98 \pm 0.32$ & $0.59 \pm 0.24$ & 1.66 \\
\hline Doxorubicin/nelfinavir & $0.02 / 5$ & $3.2 \pm\left. 0.5\right|^{*}+$ & $0.59 \pm 0.24$ & 5.42 \\
\hline \multirow[t]{3}{*}{ Atazanvir } & । & $0.43 \pm 0.04 *$ & $0.21 \pm 0.04$ & 2.04 \\
\hline & 5 & $0.93 \pm 0.14$ & $0.59 \pm 0.24$ & 1.57 \\
\hline & 10 & $0.67 \pm 0.11$ & $0.59 \pm 0.24$ & 1.17 \\
\hline Doxorubicin/atazanvir & $0.02 / 5$ & $3.76 \pm 0.30 * \dagger$ & $0.59 \pm 0.24$ & 6.37 \\
\hline \multirow[t]{5}{*}{ Ritonavir } & I & $0.26 \pm 0.022$ & $0.21 \pm 0.04$ & 1.23 \\
\hline & 2.5 & $0.31 \pm 0.03 *$ & $0.21 \pm 0.04$ & 1.47 \\
\hline & 5 & $0.25 \pm 0.08$ & $0.59 \pm 0.24$ & 0.42 \\
\hline & 10 & $0.54 \pm 0.18$ & $0.59 \pm 0.24$ & 0.91 \\
\hline & 20 & $0.34 \pm 0.15$ & $0.59 \pm 0.24$ & 0.57 \\
\hline Doxorubicin/ritonavir & $0.02 / 5$ & $3.66 \pm 0.53 * \dagger$ & $0.59 \pm 0.24$ & 6.20 \\
\hline Lopinavir & 10 & $0.72 \pm 0.14$ & $0.59 \pm 0.24$ & 1.22 \\
\hline $\begin{array}{l}\text { Doxorubicin/lopinavir/ } \\
\text { ritonavir }\end{array}$ & $0.02 / 10 / 5$ & $4.23 \pm 0.37 * \dagger$ & $0.59 \pm 0.24$ & 7.16 \\
\hline
\end{tabular}

$* P \leqslant 0.05$. Combination data were analyzed for synergism using the Bliss independence drug interaction model with a significance level of $P \leqslant 0.05$.

Table 2 Growth inhibitory concentrations $\left(\mathrm{IC}_{50}\right)$ and resistance factor (RF) to paclitaxel of parental and drug-selected SLK cell lines

\begin{tabular}{|c|c|c|c|}
\hline Treatment & $\begin{array}{l}\text { Concentration of } \\
\text { treatment }(\mu \mathrm{M})\end{array}$ & $\begin{array}{c}\mathrm{IC}_{50}(\mu \mathrm{M}) \text { to } \\
\text { paclitaxel }\end{array}$ & $\begin{array}{l}\text { RF }\left(I C_{50} / I C_{50}\right. \\
\text { SLK parent) }\end{array}$ \\
\hline None & & $0.2 \pm 0.008$ & \\
\hline \multirow{2}{*}{ Doxorubicin } & 0.02 & $1.26 \pm 0.18 *$ & 6.3 \\
\hline & 0.04 & $9.55 \pm 1.63 *$ & 47.75 \\
\hline \multirow{2}{*}{ Indinavir } & 10 & $0.11 \pm 0.04 *$ & 0.55 \\
\hline & 50 & $1.7 \pm 0.12 *$ & 8.5 \\
\hline Doxorubicin/indinavir & $0.02 / 5$ & $2.12 \pm 0.49 *$ & 10.6 \\
\hline \multirow[t]{3}{*}{ Nelfinavir } & 2 & $0.87 \pm 0.17 *$ & 4.35 \\
\hline & 5 & $1.29 \pm 0.23 *$ & 6.45 \\
\hline & 10 & $0.56 \pm 0.22 *$ & 2.8 \\
\hline Doxorubicin/nelfinavir & $0.02 / 5$ & $3.94 \pm 0.59 *^{\dagger}$ & 19.7 \\
\hline Atazanvir & 10 & $0.4 I \pm 0.08 *$ & 2.05 \\
\hline Doxorubicin/atazanvir & $0.02 / 5$ & $5.9 \pm 1.79 *^{\dagger}$ & 29.5 \\
\hline Ritonavir & 5 & $0.44 \pm 0.11 *$ & 0.42 \\
\hline Doxorubicin/ritonavir & $0.02 / 5$ & $3.66 \pm 0.53^{* \dagger}$ & 2.2 \\
\hline Lopinavir & 10 & $0.33 \pm 0.05 *$ & 1.65 \\
\hline $\begin{array}{l}\text { Doxorubicin/lopinavir/ } \\
\text { ritonavir }\end{array}$ & $0.02 / 10 / 5$ & $243.73 \pm 45 *^{\dagger}$ & 1218.65 \\
\hline
\end{tabular}

$* P \leqslant 0.05$. Combination data were analyzed for synergism by using the Bliss independence drug interaction model with a significance level of $P \leqslant 0.05$.

Next, we determined whether HIV-PI-treated SLK cell lines show cross-resistance to paclitaxel. Resistance to this compound is even more significant than that observed for doxorubicin, because of the fact that almost all tested cell lines show significantly higher IC $_{50}$ values compared with parental SLK cells, with a resistance factor ranging from 2.05 to 8.5. Resistance to paclitaxel in HIV-PItreated cells revealed that ATV $1<\mathrm{RTV} 5<\mathrm{NFV} 10<\mathrm{NFV} 2<\mathrm{NF}-$ V5 $<$ IDV50 (Table 2). Furthermore, nelfinavir-treated SLK cell lines were also challenged with the liposomal formulation of doxorubicin (Doxil). Also in this case, NFV5 cells were significantly more resistant compared with SLK parent cells $\left(\mathrm{IC}_{50}: 3.626 \pm 0.558\right.$ vs $2.037 \pm 0.628$ for NFV5 cells and SLK parent cells, respectively; $P<0.05)$. Importantly, when resistant SLK cell lines were maintained for $>20$ days in culture in the absence of doxorubicin and HIV-PIs, the MDR phenotype remained stable.

\section{Long-term co-treatment with doxorubicin and HIV-PIs acts synergistically on SLK cell line sensitivity}

Analysis of SLK cells co-exposed to doxorubicin and HIV-PIs suggests a synergistic effect between these two compounds (Table 1). Co-treated SLK cell lines show significantly increased $\mathrm{IC}_{50}$ values compared with either parental SLK cells or those exposed to the anthracycline alone (Table 1). The same trend is seen in resistance to paclitaxel except that ritonavir-treated cells are more resistant than atazanavir-treated cells (Table 2). The Bliss independence drug interaction analysis further supports the synergistic effect between doxorubicin and HIV-PIs (Tables 1 and 2). Taken together, these results suggest the following hierarchy of potency to select for resistance: D/LPV/RTV > D/RTV5 D/ATV5 > D/NFV5 > D/IDV5.

\section{HIV-PI-selected SLK cells express ABCB1 mRNA and protein}

Because of the fact that selection with HIV-PIs resulted in resistance to doxorubicin and paclitaxel, the two known substrates of ABCB1 (Gottesman et al, 2002), our next question was whether $\mathrm{ABCB} 1$ protein was upregulated in the doxorubicin- and taxolresistant SLK cell lines. Immunoblot analysis of ABCB1 expression in doxorubicin-selected cells revealed a dose-dependent increase in the expression of ABCB1 (Figure 1Aa). Overall, HIV-PI treatment of SLK cells resulted in an inverse correlation between the levels of ABCB1 expression and the concentration of the HIVPI used for selection. For example, selection of SLK cells with $1 \mu \mathrm{M}$ atazanavir resulted in a higher level of $\mathrm{ABCB} 1$ expression than selection with 5 or $10 \mu \mathrm{M}$ atazanavir (Figure 1Ad). The same basic trend was seen for all HIV-PIs, with the exceptions of indinavir (Figure 1Ab) and lopinavir (Figure 1Af). Selection of SLK cells with increasing physiological concentrations of lopinavir resulted in increased levels of ABCB1. The identity of the HIV-PIs was also important in determining the levels of $\mathrm{ABCB} 1$ protein expression where: NFV $>$ RTV $>$ ATV $>$ LPV $>$ IDV. These complex dose responses to HIV-PIs suggest a biphasic or multiphasic response of ABCB1 expression to HIV-PI treatment with inhibition of expression at higher HIV-PI levels.

Next, we determined the effect of combining either two HIV-PIs or co-treatment of doxorubicin and an HIV-PI on ABCB1 expression. The combination of lopinavir/ritonavir in a $4: 1$ ratio (Cvetkovic and Goa, 2003) resulted in a significant decrease of ABCB1 expression (Figure 1Af). SLK cell lines co-treated with doxorubicin and an HIV-PI showed higher levels of ABCB1 expression than with HIV-PI treatment alone. The synergistic increase in ABCB1 expression seen in cells co-treated with HIV-PIs and doxorubicin revealed that D/LPV/RTV $>$ D/ATV5 $>$ D/RTV5 $>$ D/NFV5 $>$ D/IDV5 (Figure 1A). Not only did all the doxorubicin and HIV-PI-treated and co-treated resistant SLK cell lines express more ABCB1 than parental cell lines, but the levels of $A B C B 1$ expressed correlated well with the levels of resistance (Figure 1A and Table 1). However, indinavir-selected SLK cell lines expressed the least amount of $\mathrm{ABCB} 1$, but were the most resistant to doxorubicin (Figure $1 \mathrm{Ab}$ and Table 1). These data suggest that indinavir-selected SLK cell lines may be doxorubicin-resistant in an $\mathrm{ABCB} 1$-independent manner.

Next, we determined whether upregulation of ABCB1 protein in response to HIV-PI treatment alone or co-treatment with HIV-PIs 
A

a
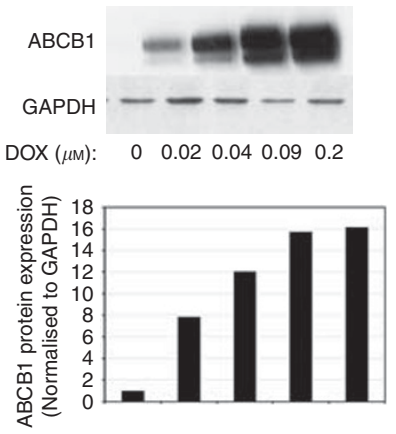

C
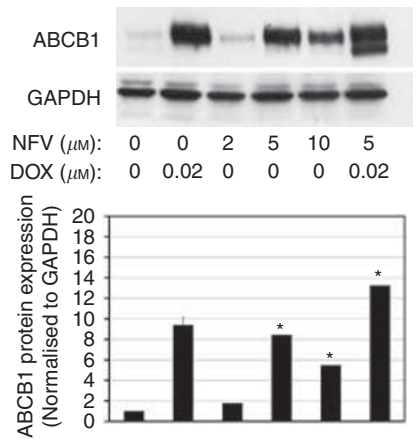

e
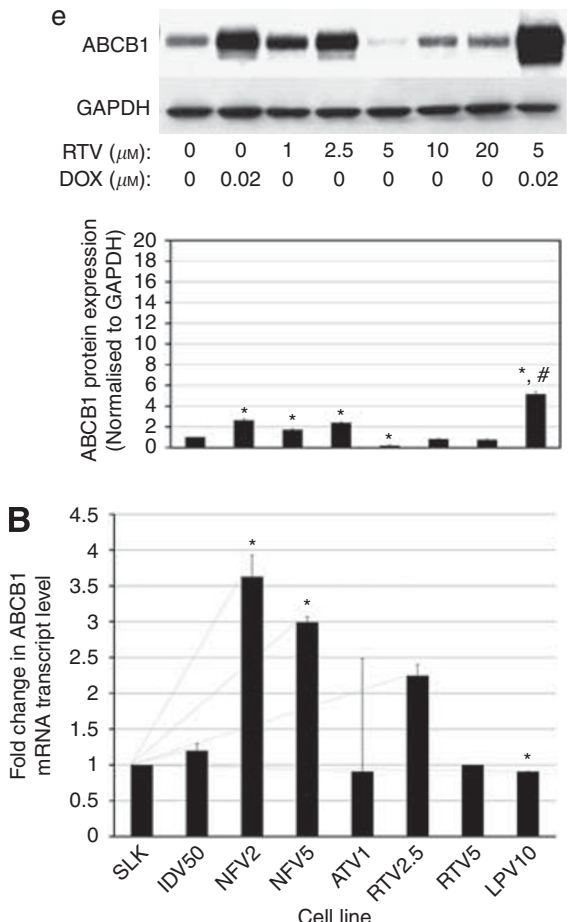

b
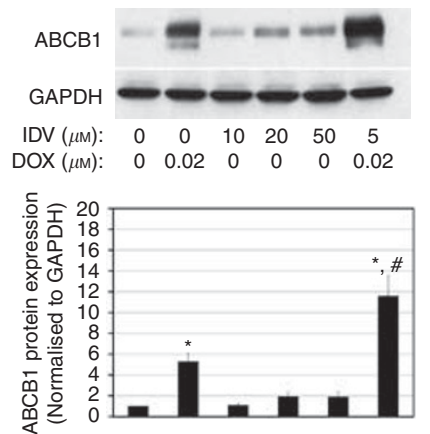

d
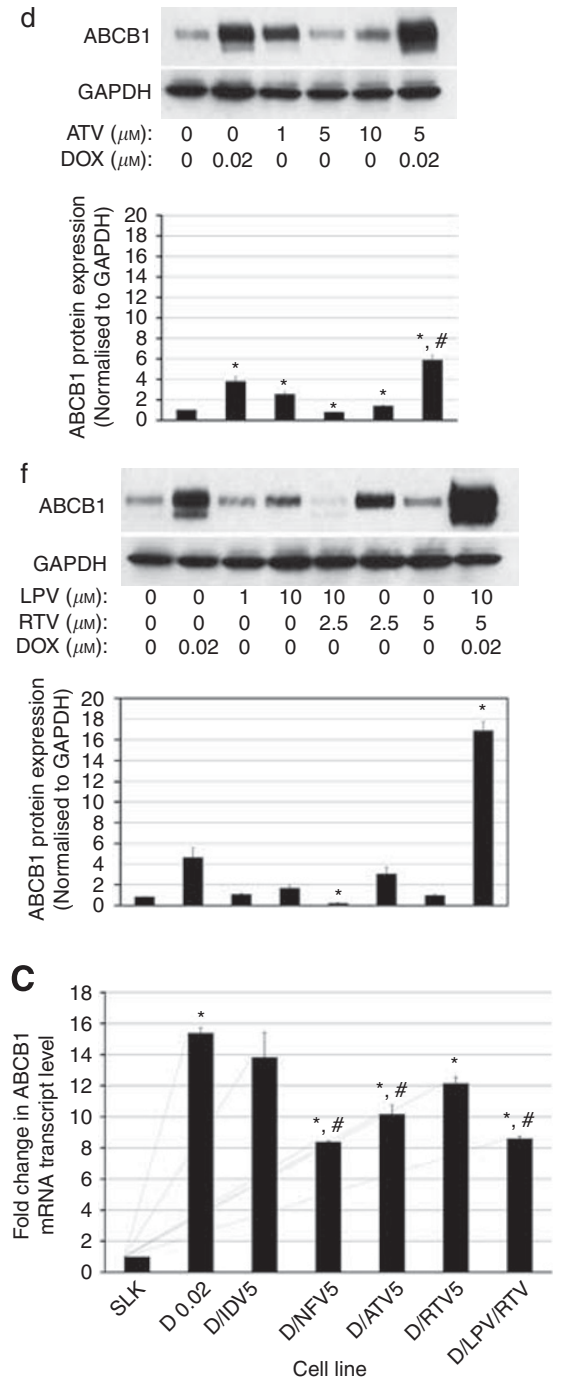

Figure I $A B C B \mid$ expression at the mRNA and protein levels in SLK cell lines selected with HIV-PIs alone or in combination with doxorubicin. (A-C) SLK cell lines treated with delivery group alone, various concentrations of doxorubicin (D) alone (a), various concentrations of either indinavir (IDV; b), nelfinavir (NFV; c), atazanavir (ATV; d), ritonavir (RTV; e), lopinavir (LPV; f), lopinavir/ritonavir (LPV/RTV; $f$ ), or co-treated with $0.02 \mu \mathrm{M}$ doxorubicin and the indicated HIV-PIs for 6-8 months. (A) Cells were harvested, lysed, resolved by SDS-PAGE gels, and analysed by western blotting with ABCBI and GAPDH, the loading control. Bar graphs represent quantification of $A B C B I$ protein expression normalised to GAPDH. Data are presented as mean \pm s.e.m. Protein from KB-3-I cells and $A B C B I$-overexpressing KB-VI cells served as controls for specificity of the ABCBI antibody. The analysis was repeated three times with protein extracts from separate cell lysates. (B and C) Cells were harvested and total RNA from SLK cells treated with various concentrations of HIV-PIs alone $(\mathbf{B})$ or in combination with $0.02 \mu \mathrm{M}$ doxorubicin $(\mathbf{C})$ was purified and analysed by qRT-PCR analysis with primers selective for ABCBI and I8S, the control. Data represent transcript levels \pm s.d. normalised to ABCBI mRNA transcript levels from SLK parental cells. ${ }^{*} P<0.05$ vs SLK parent cells, ${ }^{\#} P<0.05$ vs D0.02.

and doxorubicin resulted in altered ABCB1 mRNA levels. Total mRNA was purified and analysed by qRT - PCR for ABCB1 and the amount of ABCB1 mRNA transcript level was normalised to $18 \mathrm{~S}$ mRNA expression. When ABCB1 mRNA levels of resistant HIV-PI- treated SLK cell lines were compared with the levels present in the parental SLK cell line, ABCB1 mRNA levels in NFV2 $>$ NFV5 $>$ RTV2.5 $>$ IDV50 $>$ ATV1 (Figure 1B). These levels did not correspond well to the degree of doxorubicin resistance 
found in the cytotoxicity assays. The levels of ABCB1 mRNA found in the doxorubicin and HIV-PI co-treated SLK cell lines revealed that $\mathrm{D} .02>\mathrm{D} / \mathrm{IDV} 5>\mathrm{D} / \mathrm{RTV} 5>\mathrm{D} / \mathrm{ATV} 5>\mathrm{D} / \mathrm{NFV} 5>\mathrm{D} / \mathrm{LPV} / \mathrm{RTV}$ (Figure 1C). These results also did not correspond well with the degree of resistance to doxorubicin.

\section{SLK cell lines treated with HIV-PIs alone or in combination express functional $\mathrm{ABCB} 1$ at the cell surface}

Because of the fact that western blotting of whole cell lysates does not reveal protein location, we next investigated whether treatment with HIV-PIs alone or in combination with doxorubicin altered ABCB1 localisation in SLK cells using immunofluorescence and FACS. The SLK cells treated with HIV-PIs alone or in combination with doxorubicin were grown on coverslips, permeabilised, fixed, probed with MRK-16, an antibody that recognises the extracellular epitope of $\mathrm{ABCB} 1$, and visualised with a secondary antibody conjugated with Alexa Fluor 488. The confocal images revealed that $\mathrm{ABCB} 1$ was primarily localised to the plasma membrane and that $\mathrm{ABCB} 1$ expression profiles correlated well with western blotting expression profiles (Figure 2A).

Next, the expression of $A B C B 1$ at the plasma membrane was quantified using FACS analysis. The ABCB1 expression on SLK cells treated with HIV-PIs alone or in combination with doxorubicin was probed with MRK16, visualised with a secondary antibody conjugated to Alexa Fluor 488, and analysed using FACS analysis. We observed a significant increase of surface ABCB1 expression, which correlated with the degree of doxorubicin resistance (Figure 2B and $\mathrm{C}$ ) except in the case of ritonavir 2.5 (RTV2.5; Figure 2B and C). Therefore, either the activity of ABCB1 is greatly increased in these cells or there are $\mathrm{ABCB} 1$-independent mechanisms of resistance to doxorubicin.

Although $\mathrm{ABCB} 1$ is expressed at the cell surface, it may not be functional. Therefore, ABCB1 function was assessed with an ABCB1 fluorescent substrate, Rh123 (Lee et al, 1994). Efflux was measured in SLK cell lines treated with HIV-PIs alone or in combination with doxorubicin. Controls were the ABCB1-expressing KB-V1 cell line and its non-ABCB1-expressing parental KB-3-1 cell line. A significant increase of the efflux activity in all resistant SLK cell lines as well as KB-V1 cells was observed compared with parental cells (Figures $3 \mathrm{~A}-\mathrm{D}$ ). A representative experiment showing Rh123 efflux by HIV-PI-selected SLK cell lines (Figure 3A, upper panel) and co-selected SLK cell lines (Figure 3B, upper panel) is shown. To confirm ABCB1-dependent efflux, CsA, an inhibitor of ABCB1 efflux function (Foxwell et al, 1989), was used. The Rh123 efflux was almost completely abolished by $5 \mu \mathrm{M}$ CsA in all resistant SLK cell lines as well as the ABCB1-expressing $\mathrm{KB}-\mathrm{V} 1$ positive control cell line, as documented by the shift of the histograms towards higher levels of Rh123-related fluorescence (Figures $3 \mathrm{~A}$ and $\mathrm{B}$, lower panels), further suggesting that cells treated with HIV-PIs alone or in combination with doxorubicin express functional plasma membrane localised ABCB1.

\section{Short-term treatment shows that doxorubicin induces ABCB1 expression, whereas HIV-PI treatment selects for ABCB1 expression in SLK cells}

Because of the fact that all treatment combinations resulted in $\mathrm{ABCB} 1$ expression, we next determined whether $\mathrm{ABCB} 1$ expression is a result of induction and/or selection. Therefore, SLK cells were incubated for $72 \mathrm{~h}$ in the presence of one of the HIV-PIs alone or in combination with doxorubicin. Expression profiles for ABCB1 mRNA and protein were determined using qRT - PCR and western blotting, respectively. Short-term treatment of SLK parental cells with increasing concentrations of doxorubicin alone resulted in a concentration-dependent increase in $\mathrm{ABCB} 1 \mathrm{mRNA}$ and protein (Figures $4 \mathrm{~A}$ and $\mathrm{B}$ ). Treatment with any one of the HIV-PIs alone did not alter ABCB1 expression, with the exception of cells treated with $5 \mu \mathrm{M} \mathrm{NFV}, 10 \mu \mathrm{M} \mathrm{NFV}$, and $10 \mu \mathrm{M} \mathrm{LPV}$, which resulted in decreased levels of ABCB1 mRNA and protein compared with SLK parental cells (Figures 4A and B). Co-treatment of SLK cells with $10 \mu \mathrm{m} \mathrm{LPV}$ plus $2.5 \mu \mathrm{m}$ RTV or $0.02 \mu \mathrm{m}$ doxorubicin plus $10 \mu \mathrm{m} \mathrm{LPV}$ and $5 \mu \mathrm{M}$ RTV also resulted in decreased ABCB1 expression at the mRNA and protein levels (Figures $4 \mathrm{~A}$ and $\mathrm{B}$ ). Whereas cotreatment with doxorubicin plus an HIV-PI increased ABCB1 expression levels for each of the HIV-PIs, levels of ABCB1 did not differ from treatment with doxorubicin treatment alone (Figures $4 \mathrm{~A}$ and $\mathrm{B})$. Therefore, doxorubicin induces $\mathrm{ABCB} 1$ expression in SLK cells, whereas treatment with HIV-PIs alone selects for cells expressing ABCB1.

\section{DISCUSSION}

The present study shows that extended exposure to physiologically relevant concentrations of HIV-PIs selects for a stable MDR phenotype in a fully transformed KS-derived cell line. In addition, HIV-PIs act synergistically with the anthracycline doxorubicin to select for higher levels of ABCB1 (Figures 1A and 2). These observations may be of particular interest given the growing problem of cancer in the HIV-infected populations and the antitumour activity shown by HIV-PIs.

Despite a decrease in incidence, likely because of the reversal of immunosuppression that follows antiretroviral treatment initiation, KS remains a disease with a wide spectrum of severity. In particular, recurrence and/or disease progression despite chemotherapy and/or successful antiretroviral therapy are not uncommon (Maurer et al, 2007; Bower et al, 2008; Sullivan et al, 2009), suggesting that immune reconstitution alone may not be the unique mechanism able to influence KS clinical outcome (Pellet et al, 2001). Drug-transporting $\mathrm{ABC}$ transporters, including $A B C B 1$, were found to be associated with acquired MDR in cancer cells. Although clinically suspected (Presant et al, 1993), the MDR phenomenon has never been fully characterised in KS spindle cells that have been found to express ABC transporters (Schwartsmann et al, 1989; Gupta et al, 1998). In light of this, we started by analysing the effect on SLK cells of long-term exposure to doxorubicin. Our results show that this compound is able to induce dose-dependent resistance together with a significant crossresistance to the taxane compound paclitaxel, suggesting ABCB1related resistance (Tables 1 and 2 and Figure 4). The increased expression of $\mathrm{ABCB} 1$ at the mRNA and protein levels, as well as its active functional status, strongly supports this hypothesis (Figure 1Aa and data not shown).

As KS-derived spindle cells are able to develop a stable MDR phenotype when challenged with common cytotoxic compounds, we next analysed whether HIV-PIs may act similarly. Five different HIV-PIs (i.e., IDV, NFV, ATV, RTV, and LPV) were chosen based on their known ability to act as substrates for ABC transporters (Lee et al, 1998; Srinivas et al, 1998; Vishnuvardhan et al, 2003) and their antitumour properties (Bernstein and Dennis, 2008; Chow et al, 2009). These compounds were tested either alone or together with doxorubicin at concentrations in line with those achieved in HIV-infected patients undergoing antiretroviral treatment. Our data clearly highlight the ability of low and completely physiological concentrations of HIV-PIs to select for an MDR phenotype through increased ABCB1 expression and function in KS-derived spindle cells (Figures 1-3). Interestingly, the mechanisms resulting in $\mathrm{ABCB} 1$ expression of doxorubicin and HIV protease inhibitors are different. Whereas doxorubicin induced $A B C B 1$ expression and functionality in SLK cells after acute treatment $(72 \mathrm{~h}), \mathrm{ABCB} 1$ was only expressed in SLK cells after chronic treatment (6 months) with HIV-PIs.

Nevertheless, resistance for each of the HIV-PI selected cell lines may result from alterations in other $A B C$ transporters, as some inhibitory activity of at least one HIV-PI has been shown for 11 
A
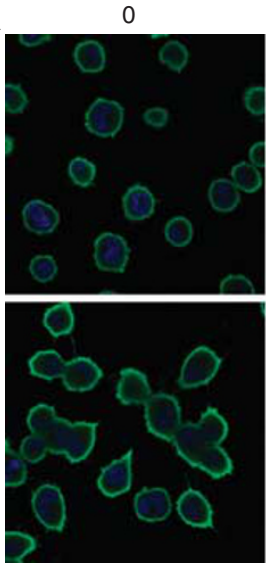

0
IDV50
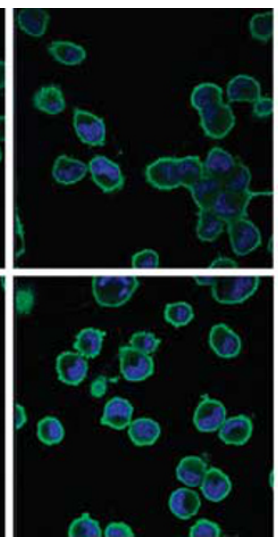

IDV5
NFV5
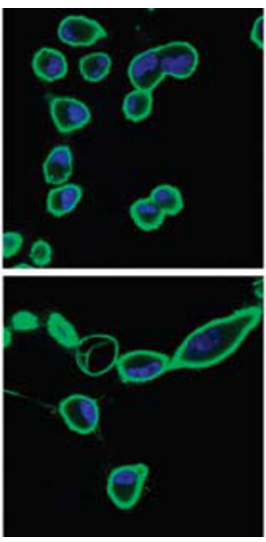

NFV5
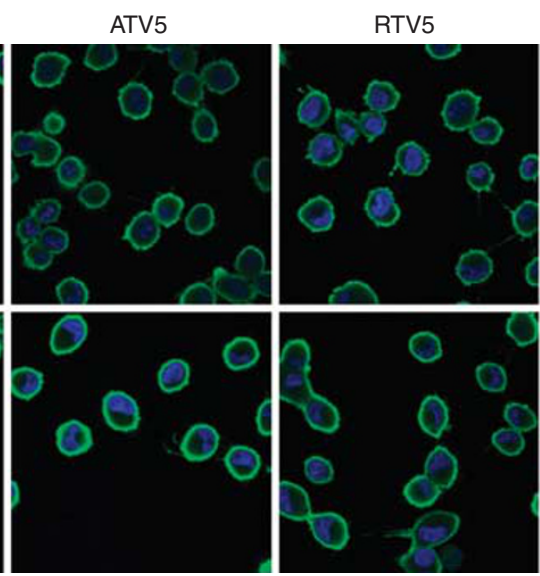

ATV5

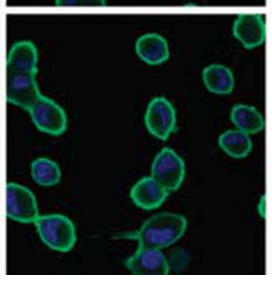

RTV5

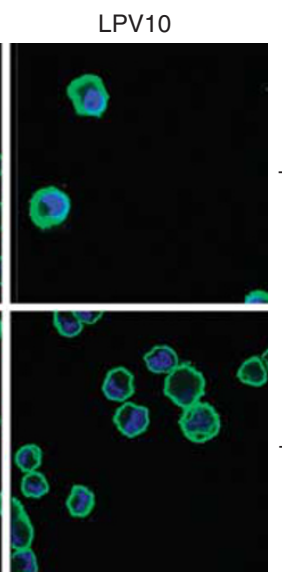

LPV/RTV
B
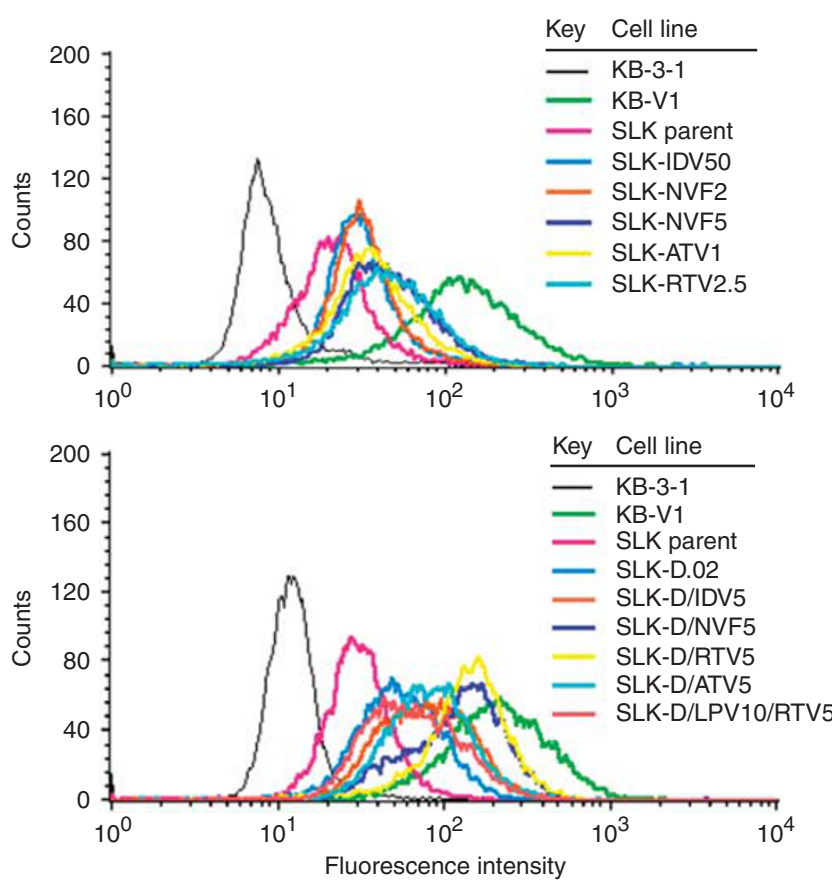

C
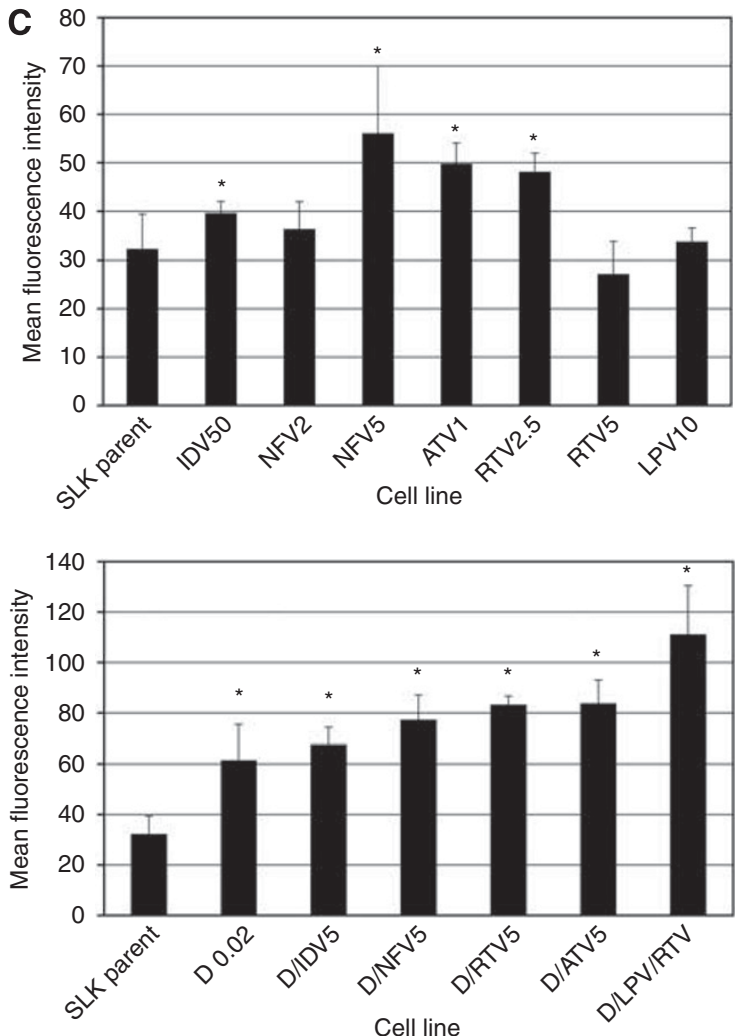

Figure 2 Localisation of ABCBI expression in SLK cell lines selected with HIV-Pls alone or in combination with doxorubicin. (A) Confocal immunofluorescent images of $\mathrm{ABCB}$ l expression in SLK cell lines treated with delivery group alone, $0.02 \mu \mathrm{M}$ doxorubicin (DOX) alone, $50 \mu \mathrm{M}$ indinavir (IDV50), $5 \mu \mathrm{M}$ nelfinavir (NFV5), $5 \mu \mathrm{M}$ atazanavir (ATV5), $5 \mu \mathrm{M}$ ritonavir (RTV5), I0 $\mu \mathrm{M}$ lopinavir (LPVI0), I0 $\mu \mathrm{M}$ lopinavir plus $5 \mu \mathrm{M}$ ritonavir (LPV/RTV), or co-treated with $0.02 \mu \mathrm{M}$ doxorubicin and the indicated HIV-PIs for 6-8 months. (B) Histogram generated from a FACS analysis of the SLK parental cells selected with nothing (SLK parental), $50 \mu \mathrm{M}$ indinavir (IDV50), $2 \mu \mathrm{M}$ nelfinavir (NFV2), $5 \mu \mathrm{M}$ nelfinavir (NFV5), I $\mu \mathrm{M}$ atazanavir (ATVI), $2.5 \mu \mathrm{M}$ ritonavir (RTV2.5), $5 \mu \mathrm{M}$ ritonavir (RTV5), or $10 \mu \mathrm{M}$ lopinavir (LPVI0) incubated with anti-ABCBI and visualised with Alexa Fluor 488 conjugated goat anti-mouse (upper panel). The lower panel is generated in the same fashion for SLK cells selected with $0.02 \mu \mathrm{M}$ doxorubicin alone (D0.02) or $5 \mu \mathrm{M}$ of indinavir (D/IDV5), nelfinavir (D/NFV5), atazanavir (D/ATV5), ritonavir (D/RTV5), or $10 \mu \mathrm{M}$ lopinavir plus $5 \mu \mathrm{M}$ ritonavir (D/LPV/RTV) in combination with 0.02 $\mu \mathrm{M}$ doxorubicin. KB-3-I cells and ABCBI-overexpressing KB-VI cells were used as negative and positive controls for protein expression, respectively. (C) Bar graphs represent the mean \pm s.d. of $A B C B I$ expression from resistant HIV-PI-selected SLK cell lines (upper panel) and from resistant HIV-PI and doxorubicin co-selected SLK cell lines (lower panel) from three independent experiments. $* P<0.05$.

family members of the ABC transporters (Bierman et al, 2010). Included in this list is $\mathrm{ABCG}$, an $\mathrm{ABC}$ transporter that has also been associated with MDR in certain cancers (Gottesman et al, 2002; Szakacs et al, 2006). Although we did not find this transporter significantly expressed at the protein level in SLK cell lines, the role of other drug transporters and/or other mechanism/s of drug resistance cannot be ruled out. These findings may be of particular interest as other common drugs employed in nonneoplastic diseases that are substrates for the $\mathrm{ABC}$ transporters have been reported to select for increased ABCB1 in tumour cells following in vivo treatment (Herzog et al, 1993) and to confer resistance to doxorubicin in a tumour system (Granzotto et al, 
A
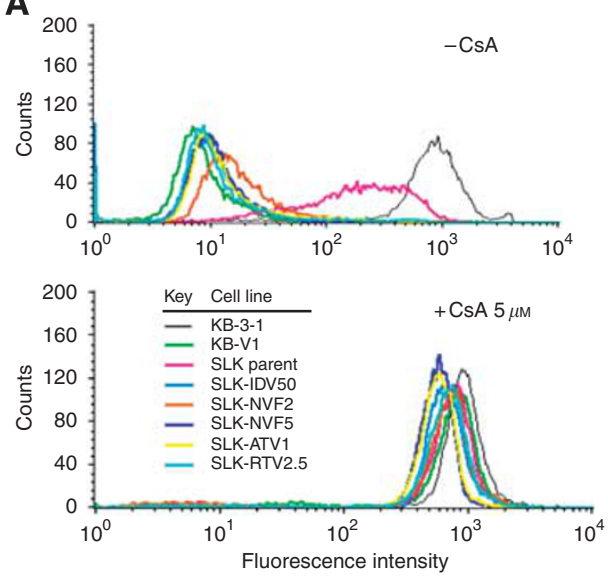

C

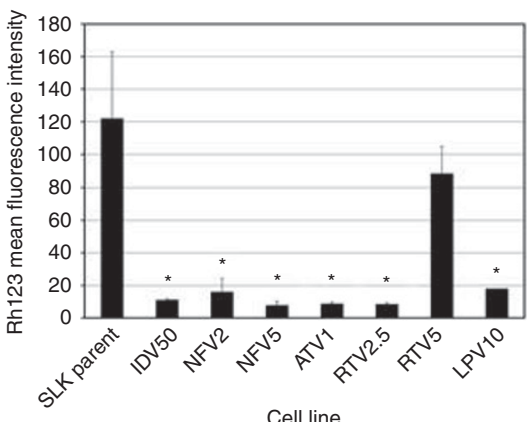

B
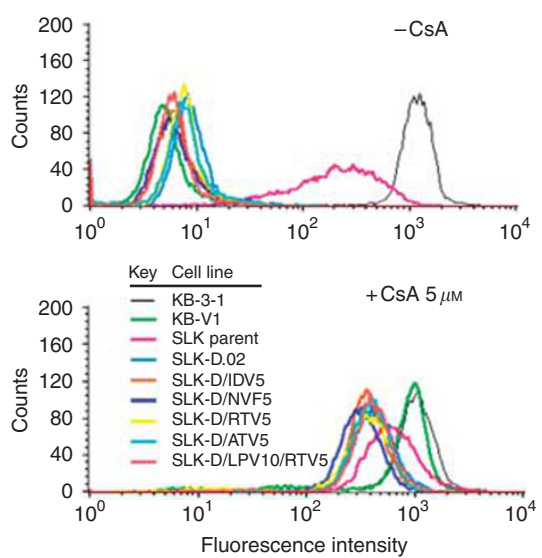

D

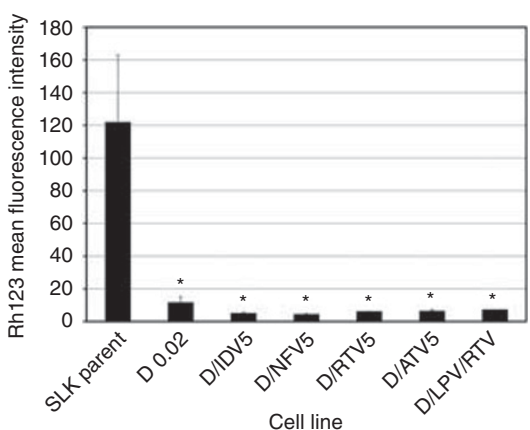

Figure $3 \mathrm{ABCBI}$-dependent efflux of rhodamine $123(\mathrm{Rh} / 23)$ in resistant SLK cells selected with HIV-Pls alone or in combination with doxorubicin (A) Histograms represent FACS analysis of Rh 123 absorbance in SLK cells selected with nothing (SLK parent), $50 \mu \mathrm{M}$ indinavir (IDV50), $2 \mu \mathrm{M}$ nelfinavir (NFV2), $5 \mu \mathrm{M}$ nelfinavir (NFV5), I $\mu \mathrm{M}$ atazanavir (ATVI), $2.5 \mu \mathrm{M}$ ritonavir (RTV2.5), $5 \mu \mathrm{M}$ ritonavir (RTV5), or $10 \mu \mathrm{M}$ lopinavir (LPV I0) after incubation in IMDM supplemented with $1.3 \mu \mathrm{M}$ Rh 123 in the presence and absence of an ABCBI selective inhibitor cyclosporine $A$ (CsA) for 45 min and resuspension in IMDM supplemented without and with $5 \mu \mathrm{M}$ CsA for $45 \mathrm{~min}$ (upper and lower panel, respectively). (B) Lower panel was generated in the same fashion for SLK cells selected with $0.02 \mu \mathrm{M}$ doxorubicin alone (D0.02) or $5 \mu \mathrm{M}$ of indinavir (D/IDV5), nelfinavir (D/NFV5), atazanavir (D/ATV5), ritonavir (D/RTV5), or $10 \mu \mathrm{M}$ lopinavir plus $5 \mu \mathrm{M}$ ritonavir (D/LPV/RTV) in combination with $0.02 \mu \mathrm{M}$ doxorubicin. The KB-3-I cells and $\mathrm{ABCB} \mid$-overexpressing KB-VI cells were used as negative and positive controls for $A B C B I$ protein function, respectively. (C) Bar graphs shows mean \pm s.d. of RhI 23 efflux values from resistant HIVPI-selected SLK cell lines and from resistant HIV-PIs and doxorubicin co-selected SLK cell lines $(\mathbf{D}) . * P<0.05$.

2004). Thus, it can be hypothesised that HIV-PIs may also exert their selection potential following in vivo administration. This may be of note as, beside AIDS-associated KS (Sgadari et al, 2002), HIV-PIs are under evaluation in a number of clinical trials as anticancer drugs for treatment of HIV-unrelated tumours, either alone (Brunner et al, 2008; Monini et al, 2009) or in association with known chemotherapeutic compounds (see http://www. clinicaltrials.gov).

Unlike the other tested HIV-PIs, indinavir requires significantly higher concentrations in order to select for an MDR phenotype (Tables 1 and 2). This may be of interest in light of the ongoing development of HIV-PIs as anticancer drugs, suggesting perhaps that some may be less likely to select for ABCB1 expression. However, $5 \mu \mathrm{m}$ of indinavir potentiates doxorubicin selection of $\mathrm{ABCB} 1$ and decreases chemosensitivity (Figure $1 \mathrm{Ab}$ and Tables 1 and 2). This synergistic effect is a common feature of all tested HIV-PIs and results from the overexpression in the plasma membrane of a functional ABCB1 protein. The overlapping of $\mathrm{ABCB} 1$ total protein, cell surface expression, and chemosensitivity hierarchies in co-selected SLK cell lines further supports this observation (Figures 1 and 2; Tables 1 and 2). Interestingly, the lopinavir/ritonavir combination shows the strongest synergistic effect when combined with doxorubicin, but when used without doxorubicin, this combination decreases $\mathrm{ABCB} 1$ protein expression, suggesting an antagonistic interaction between these two HIV-PIs (Figure 1). Moreover, these seemingly opposite results, also evident for other HIV-PIs, suggest that HIV-PIs could target different cellular pathways affecting different levels of ABCB1 regulation and/or the expression profiles of selected cells at the mRNA and protein levels. Although little is known about the signalling pathways targeted by the HIV-PIs in general, and how these pathways regulate $A B C B 1$ in particular, previous reports found that nelfinavir treatment decreased signalling through the PI3K/Akt pathway (Gupta et al, 2007), a regulator of cellular proliferation and survival in human cancer cells including KS (Vivanco and Sawyers, 2002; Chaisuparat et al, 2008). Because of the fact that Akt upregulates ABCB1 (Garcia et al, 2009), further studies should determine whether the concentration-dependent alterations in ABCB1 expression by HIV-PIs are Akt dependent. Interestingly, HIV-PIs alter the nuclear hormone receptors PXR and SXR through induction of expression and enzyme activation, respectively (Zastre et al, 2009; Dussault et al, 2001), which can also induce ABCB1 expression (Callaghan et al, 2008). Furthermore, the fact that ATV1-selected cell lines express less ABCB1 mRNA than the parental but more protein (Figures 1Ad, B and C), suggests that HIV-PIs may be involved in the post-transcriptional regulation of $\mathrm{ABCB} 1$.

Although $\mathrm{ABCB} 1$ expression correlated with increased resistance to the HIV-PIs, doxorubicin and paclitaxel, any mechanism by which a drug's toxicity is undermined is a possible mechanism of resistance, including altered transport, metabolism, and drug targets. The aetiology of KS results in abnormal regulation of cell 


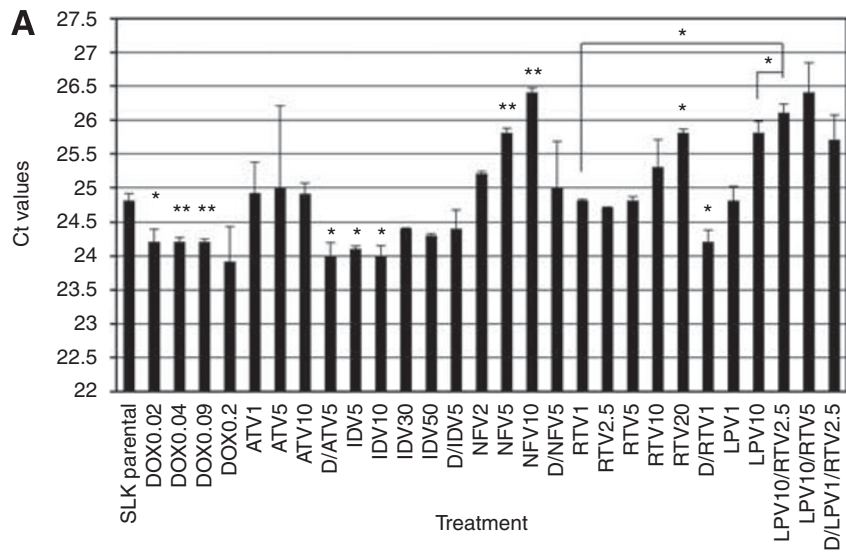

B
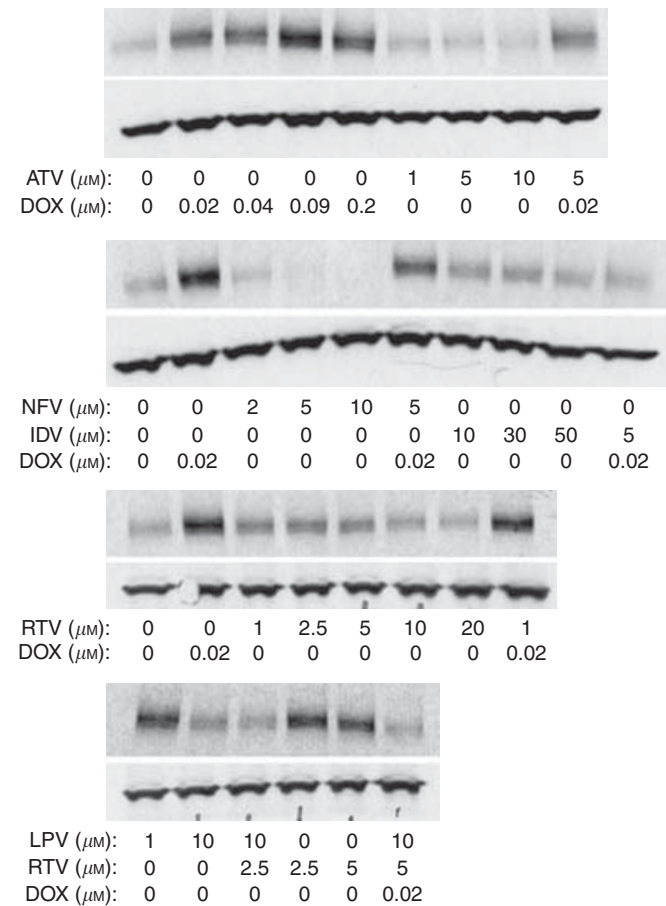

Figure 4 Whereas doxorubicin induces $A B C B I$ in SLK cells, HIV-PIs do not induce $A B C B I$ in SLK cells. The SLK cells were treated with nothing (SLK parent), 0.02, 0.04, 0.09, or $0.2 \mu \mathrm{M}$ doxorubicin (D0.02, D0.04, D0.09, or D0.2, respectively); I, 5, or $10 \mu \mathrm{M}$ atazanavir (ATVI, ATV5, or ATVI0, respectively); $5,10,30$, or $50 \mu \mathrm{M}$ indinavir (IDV5, IDV I0, IDV30, or IDV50, respectively); 2, 5, or $10 \mu \mathrm{M}$ nelfinavir (NFV2, NFV5, or NFVI0, respectively); I, 2.5, 5, 10, or $20 \mu \mathrm{M}$ ritonavir (RTVI, RTV2.5, RTV5, RTVI0, or RTV20, respectively); I or $10 \mu \mathrm{M}$ lopinavir (LPVI or LPVI0, respectively); $10 \mu \mathrm{M}$ lopinavir and $2.5 \mu \mathrm{M}$ ritonavir (LPVIO/RTV2.5); $10 \mu \mathrm{M}$ lopinavir and $5 \mu \mathrm{M}$ ritonavir (LPVI0/RTV5); or $0.02 \mu \mathrm{M}$ doxorubicin plus either $5 \mu \mathrm{M}$ of atazanavir (D/ATV5), $5 \mu \mathrm{M}$ indinavir (D/IDV5), $5 \mu \mathrm{M}$ nelfinavir (D/NFV5), I $\mu \mathrm{M}$ ritonavir (D/RTVI), or I $\mu \mathrm{M}$ lopinavir plus $2.5 \mu \mathrm{M}$ ritonavir (D/LPVI/RTV2.5) for $72 \mathrm{~h}$. (A) Bar graph of Ct values for ABCBI mRNA normalised to $18 \mathrm{~S}$, the loading control, from SLK cells treated with various concentrations of HIV-Pls alone or in combination with doxorubicin. Cells were harvested, total mRNA was purified, $A B C B \mid$ message was amplified using $\mathrm{QRT}-\mathrm{PCR}$ analysis with $\mathrm{ABCB}$ I selective primers and normalised to $18 \mathrm{~S}$, the loading control. $* P<0.1$, $* * P<0.05$. (B) Immunoblot analysis of lysates from SLK cells treated with nothing, various concentrations of doxorubicin alone, various concentrations of the five different HIV-Pls (atazanavir, indinavir, nelfinavir, ritonavir, or lopinavir) alone, various concentrations of combined HIV-PIs (ritonavir and lopinavir), doxorubicin and the different HIV-Pls, or doxorubicin plus ritonavir and lopinavir for $72 \mathrm{~h}$. Cells were harvested, lysed, resolved by SDS-PAGE gels, and analysed by western blot analysis using antibodies selective for $A B C B$ I and GAPDH, the loading control. cycle, promotion of angiogenesis, and increased anti-apoptotic signalling, which could result in inherent resistance (Dittmer and Krown, 2007). Altered regulation (transcriptional, post transcriptional, and translational) and activity of metabolic enzymes could result in inefficient metabolism of drug. The HIV-PIs alter metabolic enzyme activity/expression for CYP3A5, CYP3A4, CYP2D6, and CYP2D16 in vitro and in vivo (Antoniou et al, 2005). Altered transportation of drug that prevents it from exerting its effects could result in MDR. For example, it has been suggested that increases in transporters at the nuclear membrane prevent doxorubicin from interacting with topoisomerase, its primary known target (Bao et al, 2011). Furthermore, organic anion transporters are known as uptake transporters for HIV-PIs, and therefore alterations in these transporters could result in lowered drug seen by a cell (Janneh et al, 2008). Overall, cancer is a dynamic process; each player could play a part in MDR.

In conclusion, our study shows that KS-derived cells exposed to HIV-PIs and doxorubicin develop an MDR phenotype that correlates with $\mathrm{ABCB} 1$ protein expression in vitro. Given the growing use of concomitant chemotherapy and combined antiretroviral therapy (cART) in HIV/AIDS (Mounier et al, 2009), further studies are needed to verify if this phenomenon occurs with other antiretroviral compounds that are substrates for the $\mathrm{ABC}$ transporters and other HIV-related and HIV-unrelated cancers in vitro and in vivo in patients administered life-long cART.

\section{ACKNOWLEDGEMENTS}

This study was supported by the Intramural Research Program of the National Institutes of Health, National Cancer Institute. MBL was in part supported by a grant from FIRB: 'Costruzione di un laboratorio nazionale per lo studio dell'antibiotico-resistenza' (Resp. Professor A Cassone). We thank Mr George Leiman for editorial assistance.

\section{REFERENCES}

Aleman C, Annereau JP, Liang XJ, Cardarelli CO, Taylor B, Yin JJ, Aszalos A, Gottesman MM (2003) P-glycoprotein, expressed in multidrug resistant cells, is not responsible for alterations in membrane fluidity or membrane potential. Cancer Res 63: 3084-3091

Antoniou T, Tseng AL (2005) Interactions between antiretrovirals and antineoplastic drug therapy. Clin Pharmacokinet 44: 111-145

Bao L, Haque A, Jackson K, Hazari S, Moroz K, Jetly R, Dash S (2011) Increased expression of P-glycoprotein is associated with doxorubicin chemoresistance in the metastatic 4T1 breast cancer model. Am J Pathol 178: $838-852$

Bernstein WB, Dennis PA (2008) Repositioning HIV protease inhibitors as cancer therapeutics. Curr Opin HIV AIDS 3: 666-675

Bierman WF, Scheffer GL, Schoonderwoerd A, Jansen G, van Agtmael MA, Danner SA, Scheper RJ (2010) Protease inhibitors atazanavir, lopinavir and ritonavir are potent blockers, but poor substrates, of $A B C$ transporters in a broad panel of $\mathrm{ABC}$ transporter-overexpressing cell lines. J Antimicrob Chemother 65: $1672-1680$

Boshoff C, Weiss R (2002) AIDS-related malignancies. Nat Rev Cancer 2: 373 - 382 Bower M, Collins S, Cottrill C, Cwynarski K, Montoto S, Nelson M, Nwokolo N, Powles T, Stebbing J, Wales N, Webb A (2008) British HIV Association guidelines for HIV-associated malignancies 2008. HIV Med 9: $336-388$

Brunner TB, Geiger M, Grabenbauer GG, Lang-Welzenbach M, Mantoni TS, Cavallaro A, Sauer R, Hohenberger W, McKenna WG (2008) Phase I trial of the human immunodeficiency virus protease inhibitor nelfinavir and chemoradiation for locally advanced pancreatic cancer. J Clin Oncol 26: $2699-2706$

Callaghan R, Crowley E, Potter S, Kerr ID (2008) P-glycoprotein: so many ways to turn it on. J Clin Pharmacol 48: $365-378$

Chaisuparat R, Hu J, Jham BC, Knight ZA, Shokat KM, Montaner S (2008) Dual inhibition of PI3Kalpha and mTOR as an alternative treatment for Kaposi's sarcoma. Cancer Res 68: 8361-8368 
Chow WA, Jiang C, Guan M (2009) Anti-HIV drugs for cancer therapeutics: back to the future? Lancet Oncol 10: 61-71

Cvetkovic RS, Goa KL (2003) Lopinavir/ritonavir: a review of its use in the management of HIV infection. Drugs 63: 769-802

Dhillon T, Stebbing J, Bower M (2005) Paclitaxel for AIDS-associated Kaposi's sarcoma. Expert Rev Anticancer Ther 5: 215-219

Dittmer DP, Krown SE (2007) Targeted therapy for Kaposi's sarcoma and Kaposi's sarcoma-associated herpesvirus. Curr Opin Oncol 19: $452-457$

Dupuis ML, Flego M, Molinari A, Cianfriglia M (2003a) Saquinavir induces stable and functional expression of the multidrug transporter P-glycoprotein in human CD4 T-lymphoblastoid CEMrev cells. HIV Med 4: $338-345$

Dupuis ML, Tombesi M, Cianfriglia M (2002) Modulation of the multidrug resistance (MDR) phenotype in CEM MDR cells simultaneously exposed to anti HIV-1 protease inhibitors (PI's) and cytotoxic drugs. Ann Ist Super Sanita 38: 387-392

Dupuis ML, Tombesi M, Sabatini M, Cianfriglia M (2003b) Differential effect of HIV-1 protease inhibitors on P-glycoprotein function in multidrug-resistant variants of the human $\mathrm{CD} 4+\mathrm{T}$ lymphoblastoid CEM cell line. Chemotherapy 49: 8-16

Dussault I, Lin M, Hollister K, Wang EH, Synold TW, Forman BM (2001) Peptide mimetic HIV protease inhibitors are ligands for the orphan receptor SXR. J Biol Chem 276: 33309-33312

Evans SR, Krown SE, Testa MA, Cooley TP, Von Roenn JH (2002) Phase II evaluation of low-dose oral etoposide for the treatment of relapsed or progressive AIDS-related Kaposi's sarcoma: an AIDS Clinical Trials Group clinical study. J Clin Oncol 20: 3236-3241

Fitzgerald JB, Schoeberl B, Nielsen UB, Sorger PK (2006) Systems biology and combination therapy in the quest for clinical efficacy. Nat Chem Biol 2: $458-466$

Foxwell BM, Mackie A, Ling V, Ryffel B (1989) Identification of the multidrug resistance-related P-glycoprotein as a cyclosporine binding protein. Mol Pharmacol 36: 543-546

Garcia MG, Alaniz LD, Cordo Russo RI, Alvarez E, Hajos SE (2009) PI3K/Akt inhibition modulates multidrug resistance and activates NF-kappaB in murine lymphoma cell lines. Leuk Res 33: 288-296

Gottesman MM, Fojo T, Bates SE (2002) Multidrug resistance in cancer: role of ATP-dependent transporters. Nat Rev Cancer 2: 48-58

Granzotto M, Drigo I, Candussio L, Rosati A, Bartoli F, Giraldi T, Decorti G (2004) Rifampicin and verapamil induce the expression of P-glycoprotein in vivo in Ehrlich ascites tumor cells. Cancer Lett 205: 107-115

Gupta AK, Li B, Cerniglia GJ, Ahmed MS, Hahn SM, Maity A (2007) The HIV protease inhibitor nelfinavir downregulates Akt phosphorylation by inhibiting proteasomal activity and inducing the unfolded protein response. Neoplasia 9: 271-278

Gupta S, Aggarwal S, Nakamura S (1998) A possible role of multidrug resistance-associated protein (MRP) in basic fibroblast growth factor secretion by AIDS-associated Kaposi's sarcoma cells: a survival molecule? J Clin Immunol 18: 256-263

Herndier BG, Werner A, Arnstein P, Abbey NW, Demartis F, Cohen RL, Shuman MA, Levy JA (1994) Characterization of a human Kaposi's sarcoma cell line that induces angiogenic tumors in animals. AIDS 8: $575-581$

Herzog CE, Tsokos M, Bates SE, Fojo AT (1993) Increased mdr-1/Pglycoprotein expression after treatment of human colon carcinoma cells with P-glycoprotein antagonists. J Biol Chem 268: 2946 - 2952

Janneh O, Hartkoorn RC, Jones E, Owen A, Ward SA, Davey R, Back DJ, Khoo SH (2008) Cultured CD4T cells and primary human lymphocytes express hOATPs: intracellular accumulation of saquinavir and lopinavir. Br J Pharmacol 155: 875-883

Lee CG, Gottesman MM, Cardarelli CO, Ramachandra M, Jeang KT, Ambudkar SV, Pastan I, Dey S (1998) HIV-1 protease inhibitors are substrates for the MDR1 multidrug transporter. Biochemistry 37: 3594-3601

Lee JS, Paull K, Alvarez M, Hose C, Monks A, Grever M, Fojo AT, Bates SE (1994) Rhodamine efflux patterns predict P-glycoprotein substrates in the National Cancer Institute drug screen. Mol Pharmacol 46: 627-638
Maurer T, Ponte M, Leslie K (2007) HIV-associated Kaposi's sarcoma with a high CD4 count and a low viral load. $N$ Engl J Med 357: $1352-1353$

Monini P, Sgadari C, Grosso MG, Bellino S, Di Biagio A, Toschi E, Bacigalupo I, Sabbatucci M, Cencioni G, Salvi E, Leone P, Ensoli B (2009) Clinical course of classic Kaposi's sarcoma in HIV-negative patients treated with the HIV protease inhibitor indinavir. AIDS 23: $534-538$

Mou C, Ganju N, Sridhar KS, Krishan A (1997) Simultaneous quantitation of plasma doxorubicin and prochlorperazine content by high-performance liquid chromatography. J Chromatogr B Biomed Sci Appl 703: 217-224

Mounier N, Katlama C, Costagliola D, Chichmanian RM, Spano JP (2009) Drug interactions between antineoplastic and antiretroviral therapies: implications and management for clinical practice. Crit Rev Oncol Hematol 72: $10-20$

Nguyen HQ, Magaret AS, Kitahata MM, Van Rompaey SE, Wald A, Casper C (2008) Persistent Kaposi sarcoma in the era of highly active antiretroviral therapy: characterizing the predictors of clinical response. AIDS 22: $937-945$

O'Hara AJ, Chugh P, Wang L, Netto EM, Luz E, Harrington WJ, Dezube BJ, Damania B, Dittmer DP (2009) Pre-micro RNA signatures delineate stages of endothelial cell transformation in Kaposi sarcoma. PLoS Pathog 5: e1000389

Pellet C, Chevret S, Blum L, Gauville C, Hurault M, Blanchard G, Agbalika F, Lascoux C, Ponscarme D, Morel P, Calvo F, Lebbe C (2001) Virologic and immunologic parameters that predict clinical response of AIDSassociated Kaposi's sarcoma to highly active antiretroviral therapy. I Invest Dermatol 117: 858-863

Perloff MD, von Moltke LL, Fahey JM, Daily JP, Greenblatt DJ (2000) Induction of P-glycoprotein expression by HIV protease inhibitors in cell culture. AIDS 14: 1287-1289

Presant CA, Scolaro M, Kennedy P, Blayney DW, Flanagan B, Lisak J, Presant J (1993) Liposomal daunorubicin treatment of HIV-associated Kaposi's sarcoma. Lancet 341: 1242-1243

Sasco AJ, Jaquet A, Boidin E, Ekouevi DK, Thouillot F, Lemabec T, Forstin MA, Renaudier P, N'Dom P, Malvy D, Dabis F (2010) The challenge of AIDS-related malignancies in sub-Saharan Africa. PLoS One 5: e8621

Schwartsmann G, Cerski CT, Sander E, Sprinz E, Kronfeld M (1989) P-glycoprotein expression and AIDS-related Kaposi's sarcoma. J Natl Cancer Inst 81: 1755- 1756

Sgadari C, Barillari G, Toschi E, Carlei D, Bacigalupo I, Baccarini S, Palladino C, Leone P, Bugarini R, Malavasi L, Cafaro A, Falchi M, Valdembri D, Rezza G, Bussolino F, Monini P, Ensoli B (2002) HIV protease inhibitors are potent anti-angiogenic molecules and promote regression of Kaposi sarcoma. Nat Med 8: 225-232

Srinivas RV, Middlemas D, Flynn P, Fridland A (1998) Human immunodeficiency virus protease inhibitors serve as substrates for multidrug transporter proteins MDR1 and MRP1 but retain antiviral efficacy in cell lines expressing these transporters. Antimicrob Agents Chemother 42: 3157 - 3162

Sullivan RJ, Pantanowitz L, Dezube BJ (2009) Targeted therapy for Kaposi sarcoma. BioDrugs 23: 69-75

Szakacs G, Paterson JK, Ludwig JA, Booth-Genthe C, Gottesman MM (2006) Targeting multidrug resistance in cancer. Nat Rev Drug Discov 5: 219-234

Vishnuvardhan D, Moltke LL, Richert C, Greenblatt DJ (2003) Lopinavir: acute exposure inhibits P-glycoprotein; extended exposure induces P-glycoprotein. AIDS 17: $1092-1094$

Vivanco I, Sawyers CL (2002) The phosphatidylinositol 3-Kinase AKT pathway in human cancer. Nat Rev Cancer 2: 489-501

Zastre JA, Chan GN, Ronaldson PT, Ramaswamy M, Couraud PO, Romero IA, Weksler B, Bendayan M, Bendayan R (2009) Up-regulation of P-glycoprotein by HIV protease inhibitors in a human brain microvessel endothelial cell line. J Neurosci Res 87: 1023-1036

This work is published under the standard license to publish agreement. After 12 months the work will become freely available and the license terms will switch to a Creative Commons Attribution-NonCommercial-Share Alike 3.0 Unported License. 